\title{
THE IMPLEMENTATION OF SEISMIC ISOLATION IN THE RETROFIT OF A LARGE WHARF
}

\author{
Barry J. Davidson ${ }^{1}$, Darrin K. Bell ${ }^{2}$ and Stuart F. George ${ }^{3}$
}

\begin{abstract}
The paper describes the implementation of lead-rubber bearings as energy absorbers as part of the retrofit and upgrade of a large wharf. The key design requirement of the seismic retrofit was to ensure that the limited ductility capacity of the existing wharf piles was not exceeded. This was achieved by providing additional lateral restraint to the wharf in the form of groups of raking piles fastened to the wharf via post-tensioned lead-rubber bearings acting as energy absorbers.
\end{abstract}

\section{INTRODUCTION}

Princes wharf was designed and built for the city of Auckland in the mid 1920's. It is a large reinforced concrete structure, approximately $360 \times 90 \mathrm{~m}$ in plan and prior to retrofit it supported six two-storey cargo sheds that covered approximately $50 \%$ of its area. In its original configuration it was supported by approximately $2000500 \times 500 \mathrm{~mm}$ piles, grouped in threes to a single pile cap under the sheds, otherwise as single piles in the open deck area. Lateral movement of the wharf was restrained by a series of raked piles at the seaward end and by an indeterminate number of sea walls and retaining structures underneath the first $30 \mathrm{~m}$ of the wharf at the landward end.

The development of other wharves for container traffic over the last three decades had left Princes wharf under utilized and the city of Auckland has been looking to redevelop the waterfront in ways that will encourage people to enjoy the harbour. Thus the proposal for the construction of apartments and an international hotel on the wharf was in keeping with the city's plans. The proposal was to add an additional four storeys to the four sheds at the landward end of the wharf to provide a series of apartments, and an additional six stories to the remaining two sheds to construct a modern hotel. A perspective of the proposed concept showing the hotel at the end of the wharf is given in Figure 1(a). In this figure the existing wharf deck and piles are clearly shown.

\section{SEISMIC DESIGN CONCEPTS}

It was proposed by the designers at the outset that the redevelopment of the wharf should satisfy the design specifications for new buildings where possible. Design loading for both gravity and seismic cases were therefore determined as per the New Zealand Loadings Standard, NZS4203 (1992). The capacities of the existing vertical piles were assessed to the New Zealand Concrete Standard NZ3101 (1995), except with respect to confinement. As the piles typically had little or no confining steel it was necessary to determine the ductility and durability of the piles by special studies. These showed that the performance of the redeveloped wharf under gravity load would be satisfactory without any remedial work as it was originally designed to support cargo loads greater than the weight to be added in the redevelopment. Initial studies showed however, that the wharf in its existing or redeveloped form would be unable to satisfy modern earthquake standards. A detailed study was therefore performed to determine a means of providing adequate lateral restraint to the wharf.

The wharf piles had been driven to refusal into approximately $2 \mathrm{~m}$ of stiff soil overlaying the Waitemata bedrock. Seismic hazard studies had recommended that suitable spectra would be the NZS4203 (1992) subsoil category (a) for rock or very stiff soil scaled to a peak ground acceleration of $0.204 \mathrm{~g}$ (Beca Carter 1996) or a peak ground acceleration of $0.231 \mathrm{~g}$ (Tonkin and Taylor 1997). As there is between 2 and 6 metres of soft soil overlying the stiff soil in which the piles are embedded, a conservative approach was chosen for design purposes and the NZS 4203 subsoil category (b) spectrum for intermediate soil was selected with a peak ground acceleration of $0.32 \mathrm{~g}$. Figure 2 shows the chosen design spectrum, the spectra from the seismic hazard studies and the standard NZS4203 rock spectrum for Auckland with a peak ground acceleration of $0.408 \mathrm{~g}$. It can be seen in this figure that for periods longer than one second, the chosen spectrum aligns closely with the standard NZS4203 rock spectrum.

\footnotetext{
1 Department of Civil \& Environmental Engineering, University of Auckland, N.Z. (Member)

${ }^{2}$ Compusoft Engineering Ltd., Auckland (Member)

${ }^{3}$ Buller George Engineers, Auckland (Member)
} 


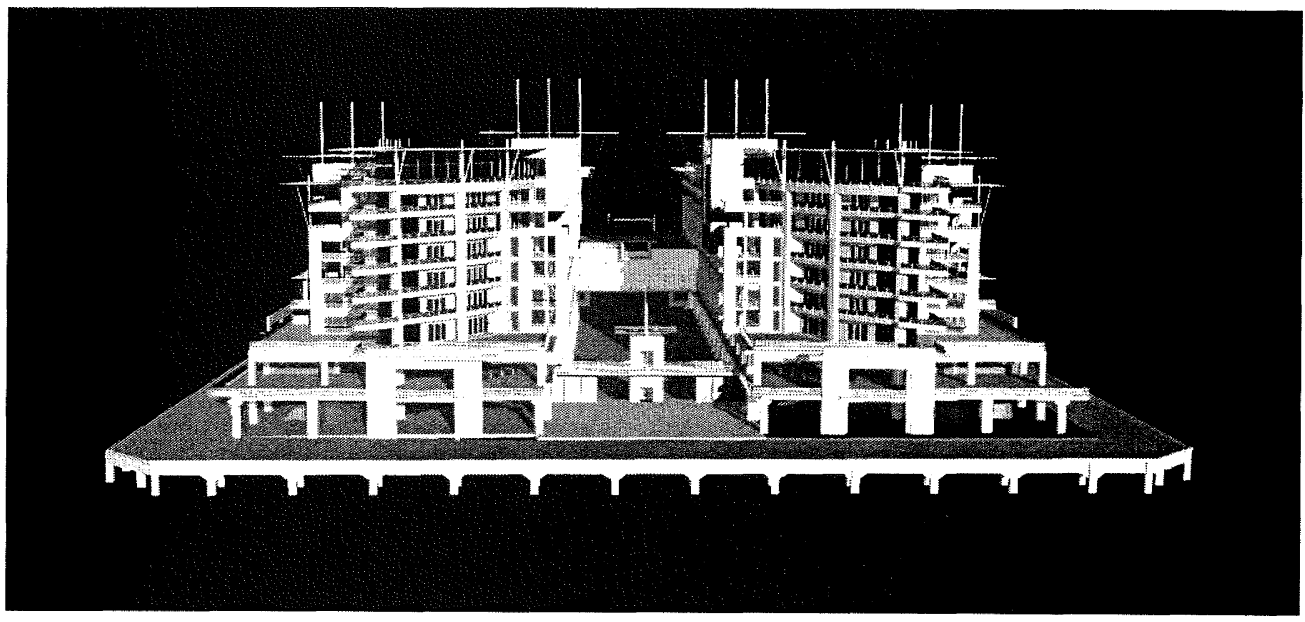

Figure 1 (a). Proposed Development (Courtesy Leuschke Group Architects).

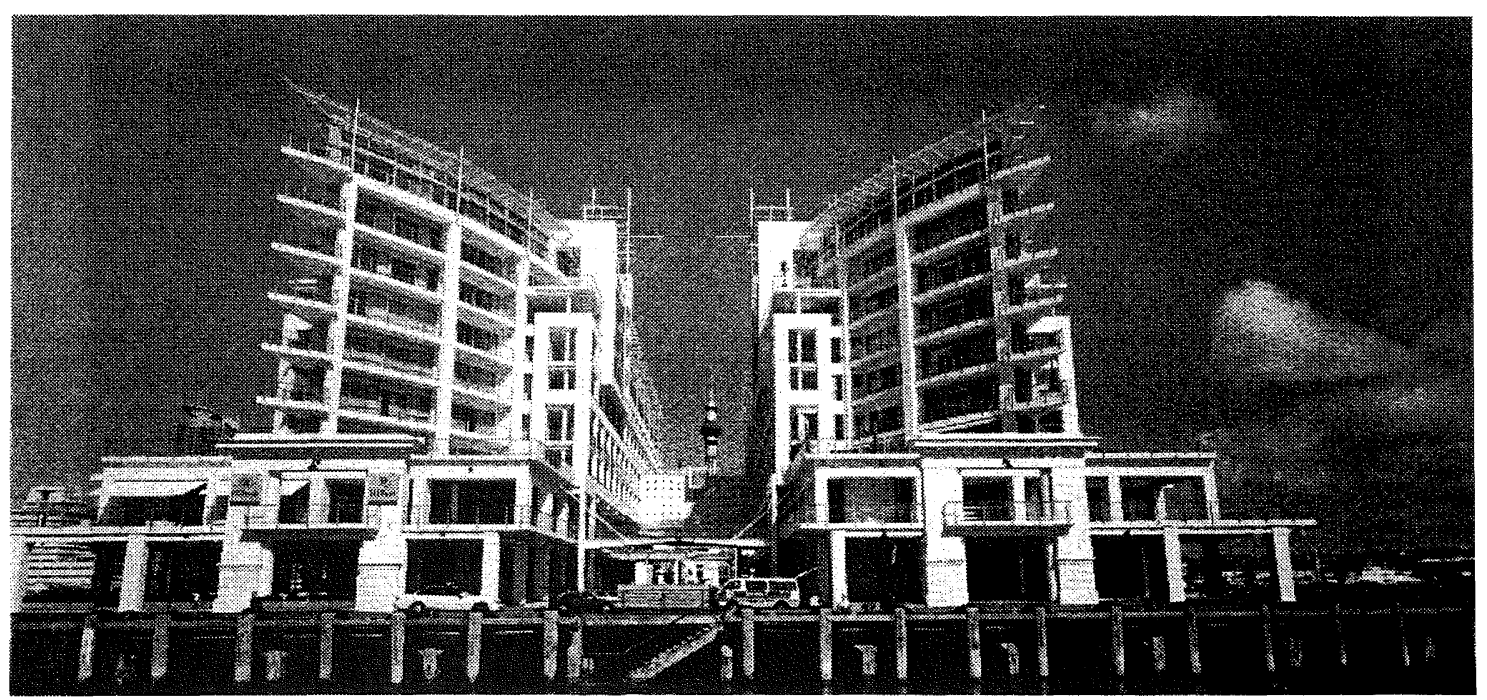

Figure 1 (b). Completed Structure (Courtesy Leuschke Group Architects). 


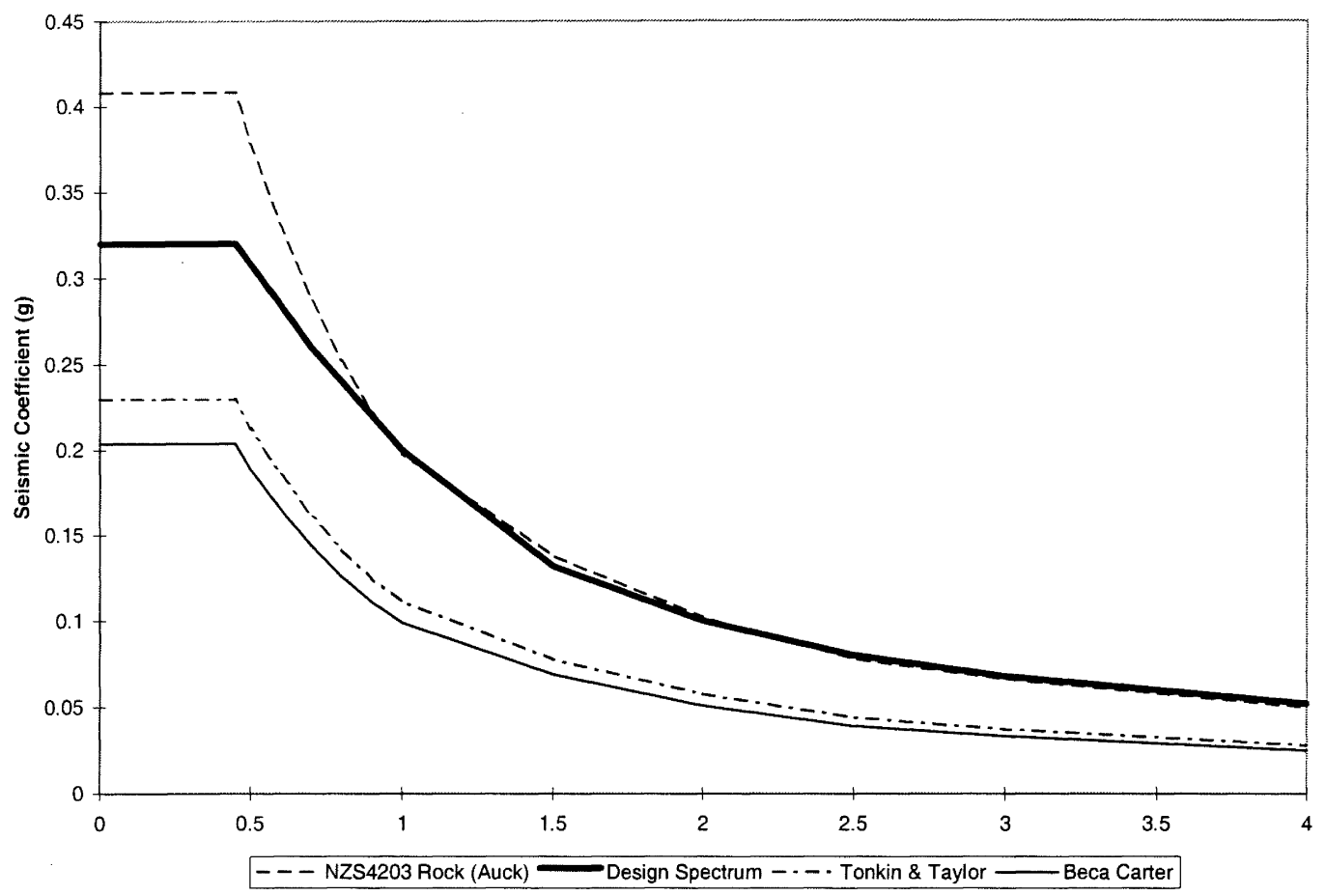

Figure 2. Design Spectra

At the preliminary stages of design it was determined that the allowable lateral deflection of the existing vertical piles would be critical in any solution and as a consequence of this, two possible means of retrofitting the wharf were proposed. Firstly the addition of fifteen groups of raking piles fastened to the underside of the wharf. These were to behave elastically at a design level earthquake. The second solution also required the addition of the raking piles but had each of the pile groups fastened to the wharf through an energy dissipating device. It was acknowledged at this early stage that there were possible additional advantages in choosing the second option in that it could lead to reductions in the design loads for the new buildings.

\section{EXISTING PILE CAPACITIES}

The wharf is supported by approximately $2000500 \times 500$ $\mathrm{mm}$ concrete piles located on a 6.1 metre grid. The piles positioned beneath the proposed wharf buildings are typically arranged in groups of three connected to the 400 $\mathrm{mm}$ wharf deck through pile caps. The pile cap depth varies between 1 and $4 \mathrm{~m}$, caste as required to bring the driven piles up to the deck level. The shortest of the single piles occur around the perimeter of the wharf where they are restrained at the top by a reinforced concrete truss system which reduces their effective length by $5 \mathrm{~m}$. The lengths of these piles vary throughout the wharf from 15 to $23 \mathrm{~m}$. The geotechnical report by Tonkin and Taylor (1997) indicates the shortest piles are in the central portion of the wharf, while the longest are at the seaward end and at localised positions at the landward end. With seismic mass of the proposed structure as approximately 110,000 tonnes, the average axial load on each pile was $550 \mathrm{kN}$. The most critical piles were the shortest that were located on the outer edge midway down the length of the wharf with a low axial load of approximately $325 \mathrm{kN}$.

The piles supporting the wharf have no shear or confining reinforcement apart from spirally bound No. 8 wire for a length of $1200 \mathrm{~mm}$ at the head and toe. Additionally they are lightly reinforced, those with the lowest axial load have only four $22 \mathrm{~mm}$ diameter plain bars. The New Zealand Concrete Standard (1995) specifies minimum requirements for transverse reinforcement for columns that are clearly not met. To assess the achievable displacement capacities of the piles the NZNSEE (1996) report for Earthquake Risk Buildings was consulted and some guidance was obtained from Professor Nigel Priestley, one of the authors of the report. In assessing the displacement capacity of the piles, the lack of confinement, the influence of the behaviour of plain bars and the low reinforcement ratio governed the calculations. It was decided that the strain in the longitudinal reinforcement should be restricted to 0.005 as discussed by Priestley et al (1996) to ensure that the possibility of bar buckling was minimized. At this level of curvature the maximum concrete strains were calculated to be approximately 0.0025 so it was expected that vertical splitting of the concrete would also be minimized.

Typical conservative allowable displacements were calculated for the critical short lightly loaded piles as 120 $\mathrm{mm}$, giving a member ductility of 2.1 , and for the more heavily loaded piles that supported the wharf structures, 200 $\mathrm{mm}$, with a ductility of 1.9 . 


\section{DYNAMIC STUDIES}

To investigate the relative performance of the two possible seismic lateral strengthening concepts two dimensional models of the wharf and proposed wharf structures were developed. In these models the influence of the existing raking piles at the seaward end of the wharf and the sea walls at the landward end were ignored as it was assumed that they would be demolished as part of the retrofit. The wharf buildings were represented by a single frame with material properties scaled so that their stiffness was equivalent to the sum of all the frames on the wharf. The model included the existing two-storey reinforced concrete frames, the additional reinforced concrete walls required to strengthen them, and the steel frames that were to be used for the additional levels. The existing vertical piles and the proposed raked piles were modelled as elastic springs, and for the isolated proposal, a bilinear spring was introduced between the raked pile spring and the base of the structure. A schematic of the model is shown in Figure 3.

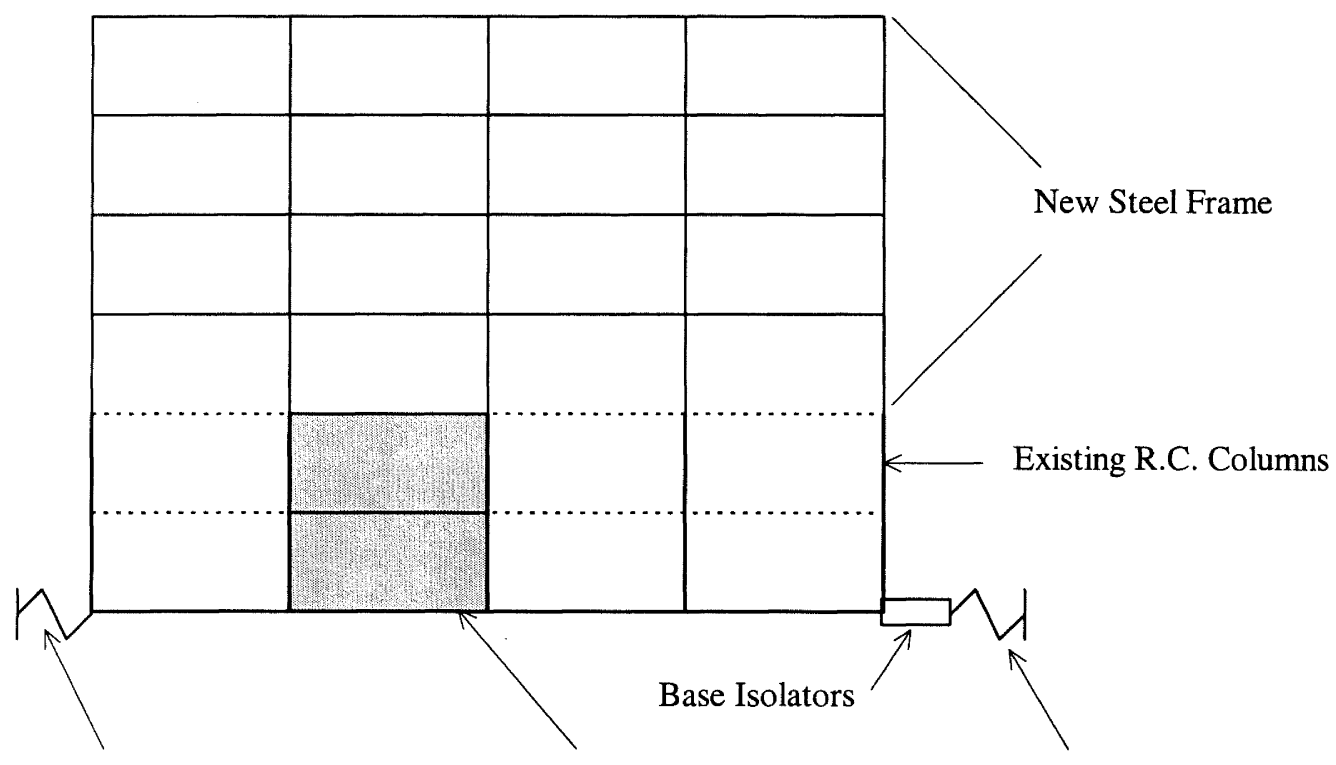

Existing Vertical Piles

New 200 R.C. Walls

New Raking Piles

Figure 3. Schematic of Dynamic Model

Both response spectra and nonlinear time history analyses were made using this model to determine the optimum stiffness and strength of additional lateral resisting systems and to investigate the sensitivity of the solutions to assumed parameters such as soil stiffness and effective section properties for the existing vertical piles. For the time history analyses, artificial earthquakes based upon the El Centro, Matahina Dam, and Hachinohe earthquakes and scaled so that their 5\% damped elastic spectra were similar to the design spectrum given in Fig. 2 were used.

The lateral stiffness of the existing vertical piles depends upon their length, the axial load, the reinforcement content and end fixities. A conservative probable average lateral stiffness for these piles was assumed as $350,000 \mathrm{kN} / \mathrm{m}$. To account for uncertainties, analyses were also performed for stiffnesses of 150,250 , and $450 \times 10^{3} \mathrm{kN} / \mathrm{m}$. The analyses assumed that 15 groups of four raked piles would be sufficient to support the wharf. For the elastic solution, 900 $\mathrm{mm}$ diameter piles were chosen and for the isolated model the diameter chosen was $650 \mathrm{~mm}$. Their effective stiffnesses were calculated allowing for skin friction for the tension piles and end bearing for those in compression. The sensitivity of the solutions to the calculated stiffnesses of the raked piles was checked by varying the calculated stiffnesses by $+/-30 \%$. The influence of variations to member size and end fixities of the proposed steel superstructure was also investigated.

The first modes of the structure with alternative support configurations are shown in Figure 4 . The flexibility of the upper floors of the wharf buildings is illustrated by the first mode of the structure with the wharf fixed. Approximately $35 \%$ of the mass of the buildings participates with this mode and the mass of the lower floors is excited in the higher modes which have periods below 0.2 seconds. Approximately 80 to $95 \%$ of the mass of the wharf and the wharf buildings participates in the first mode of the structure when nominally elastically behaving raking piles are used. The inclusion of a bilinear energy absorber extends the first mode period to approximately 2 seconds, as shown in Fig 4 with approximately $100 \%$ of the mass participating in this mode. 


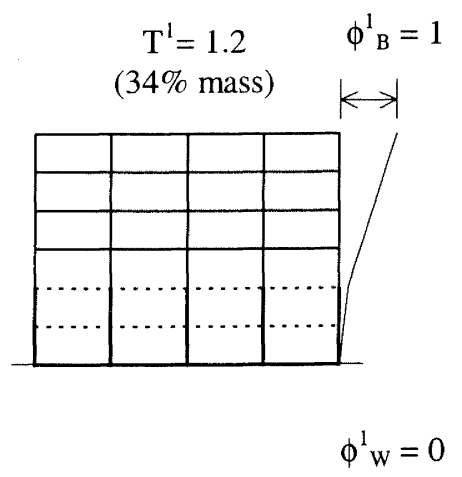

Fixed Base

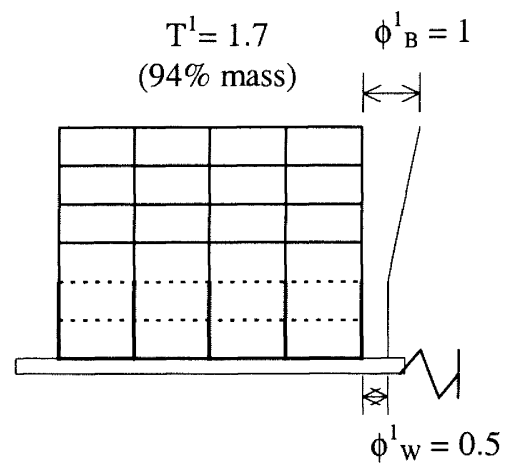

Elastically Supported Wharf

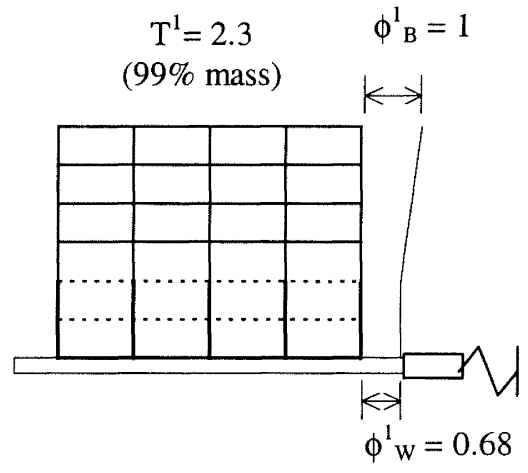

Wharf with Energy
Dissipaters

Figure 4. First Modes of the Structure

Typical displacement time histories of different levels of the wharf for both the isolated and "elastic" support solution are shown in Figure 5. These results were developed using an effective lateral stiffness of $1.3 \times 10^{6} \mathrm{kN} / \mathrm{m}$ for the "elastic" support raking piles, $0.65 \times 10^{6} \mathrm{kN} / \mathrm{m}$ for the raking piles of the isolated support system, and an 'optimal' bilinear energy shape which is described in the next section. These displacement responses follow expected trends. Thus for the isolated model, the displacement at the top of the buildings follows closely that of the wharf with little amplification and the displacement of the top of the racking piles is limited by the limitation of the force through the energy absorber. In contrast, the "elastic" support model produces larger displacements in the nominally stiffer raking piles and larger displacements in the superstructure of the wharf buildings. The conclusion of these studies of most interest was, within practical bounds, that the "elastic" solution restrained the lateral movement of the wharf only marginally more than the isolated solution. This restriction was achieved at the very high cost of large lateral "shear" forces through the "elastic' raking piles as listed in Table 1 . From the values in this table it can be seen that there were significant percentage reductions in shear at all floors in the isolated wharf. However the overall level of shear in the superstructure for both support solutions was relatively low and it was found that the increase in cost of designing for the "elastic" levels was not large. The knowledge of this minor increase in cost assisted in the decision on whether or not to disconnect the wharf from its end fixities in the final design philosophy. In contrast, the comparatively very large lateral forces that had to be transferred through the raking piles of the "elastic" supported model highlighted the isolation solution as the most economically, and viable.
From the two dimensional dynamic studies the nominal design displacement of the wharf and the top of the vertical piles was $90 \mathrm{~mm}$. This displacement was calculated using a stiffness of the vertical piles consistent with assumptions made in calculating the allowable deflection of the critical piles as $120 \mathrm{~mm}$. Further studies were undertaken to investigate the influences of; variation of the stiffness of the vertical piles, the influence of p-delta effects, and the influence of the indeterminate fixity provided by the sea walls at the landward end and the existing raking piles at the seaward end of the wharf.

It was shown that the first of these two effects had only a small effect on the design displacements of the vertical piles. By assuming that the piles were more flexible gave larger allowable design deflections and to some extent this effect was self-compensating. P-delta effects were small and provided only a slight amplification to the design displacement. However, the uncertainty in the properties of the structural systems at the wharf ends meant that torsional effects could not be evaluated with any accuracy. A sensitivity study was made using a two dimensional plan model of the wharf with various stiffnesses and strengths of the end structures. The conclusion of this study was that significant torsional behaviour could occur giving rise to a maximum increase of deflection of $30 \%$. As a consequence of these further studies the design displacement of the wharf was increased to $120 \mathrm{~mm}$ with the possibility of displacements up to the order of $140 \mathrm{~mm}$ occurring at the seaward end as a result of torsion. 
Top of Building

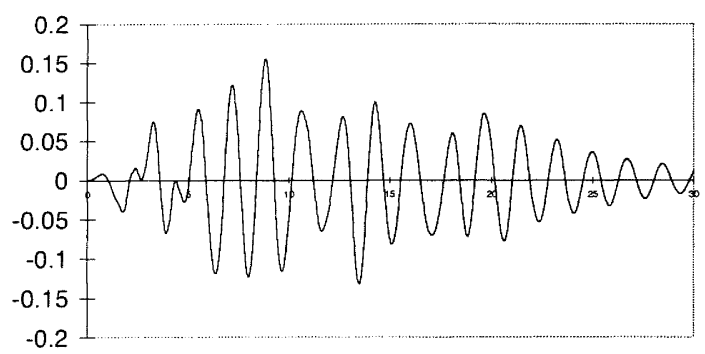

Wharf

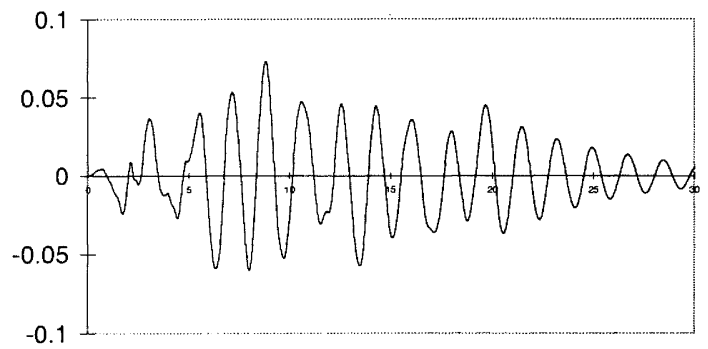

Top of Raking Piles

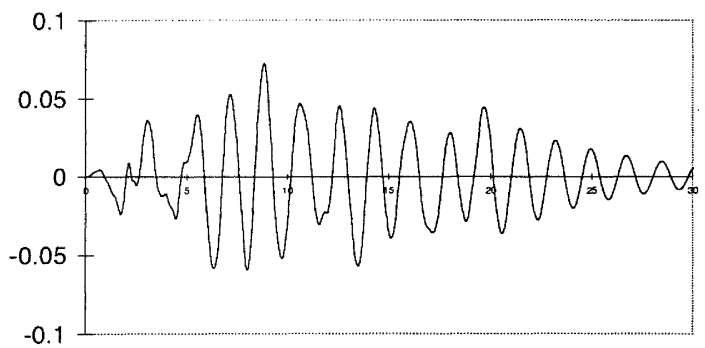

Top of Building

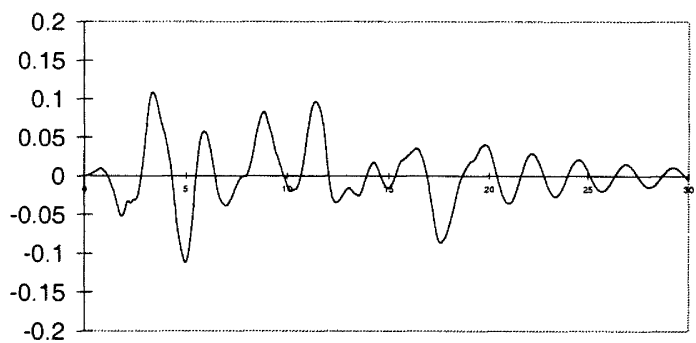

Wharf

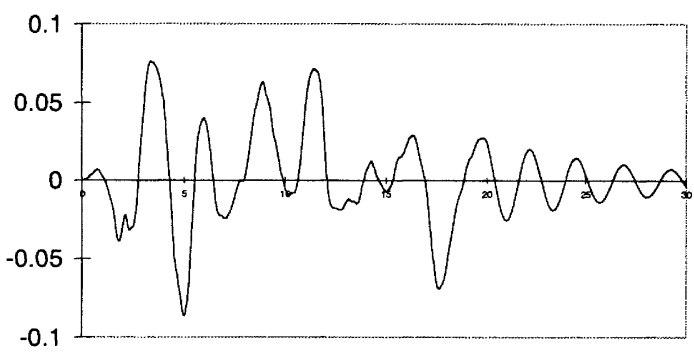

Top of Raking Piles

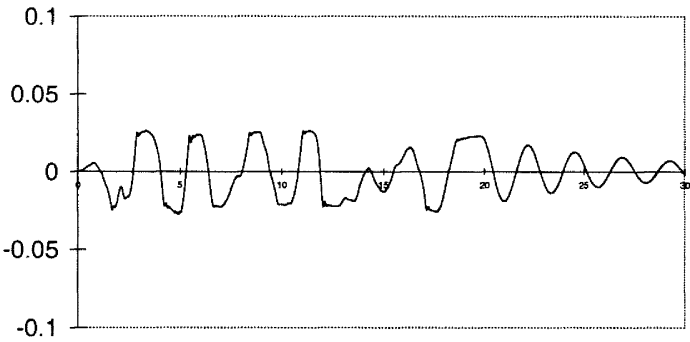

(a) "Elastic" Support

(b) Isolated Support

Figure 5. Displacements

Table 1. Inter-Storey Shears $(\mathbf{k N})$

\begin{tabular}{|c|c|c|}
\hline Storey & "Elastic" Support & Isolated Support \\
\hline 6 & 10,500 & 4,000 \\
\hline 5 & 19,000 & 7,500 \\
\hline 4 & 26,000 & 10,500 \\
\hline 3 & 34,000 & 13,500 \\
\hline 2 & 50,000 & 18,500 \\
\hline 1 & 65,500 & 24,000 \\
\hline Vertical Piles & 26,000 & 30,000 \\
\hline Raking Piles & 94,000 & 18,000 \\
\hline
\end{tabular}

This level of displacement meant that there was no ductility demand on the existing vertical piles of the wharf with the exception of some of the shortest piles midway along the wharf at its outer edges. It is possible that for a number of these piles ( that support approximately $1 \%$ of the wharf area, but no wharf structures) a ductility demand of 1.2 may be imposed. This demand is within the capacity of these piles.

\section{SEISMIC DESIGN PHILOSOPHY}

As a result of the dynamic analyses the seismic design philosophy was able to be finalized. The wharf would be strengthened by the addition of 15 groups of raking piles fastened to the underside of the existing wharf via bilinear 
acting energy absorbers. The wharf would remain attached to the existing lateral support structures at each end. These provide additional stiffness for serviceability and were costly to remove. The design of the raking piles and bearings had to ensure the vertical pile displacements did not exceed their displacement capacities under the worse case of the wharf totally free from its end supports or partially restrained. The design of the wharf structures had the same criteria. This meant that the design of these structures could not take advantage of the lower lateral forces associated with the isolated wharf, but the additional cost for the higher strength structures was small and less than the cost of freeing the wharf from its end supports.

\section{ENERGY ABSORBERS}

Many variations of a bilinear hysteretic curve for the energy absorbers were considered to obtain an optimal solution in the dynamic studies of the wharf. These variations were developed taking into consideration the constraints imposed by the designs of available energy absorbers. Two possible absorbers were considered. The first, the standard laminated steel-rubber bearing with lead plugs, the second, the (then named) Penguin energy absorber, Monti (1998). At the time of the dynamic studies both of these items of equipment had apparent advantages and drawbacks. The laminated bearing was well accepted as a reliable component when supporting a large vertical load and could be supplied competitively, but it was somewhat untested under zero axial load conditions. The suppliers of these bearings gave assurances that a satisfactory performance of the bearings could be designed for. In contrast the Penguin energy absorbers were specifically designed for a zero vertical load situation, however at the time of these studies only unidirectional absorbers had been developed. Robinson Seismic Ltd. have since developed a two directional acting absorber.

The best performance of the wharf was achieved with the absorber force deflection relationship approaching an "elasto-plastic" shape with a high initial or elastic stiffness. After the tender process the laminated lead-rubber bearing was chosen, and with consultation with the suppliers an absorber curve that would provide acceptable wharf displacements was agreed upon. This is shown in Figure 6.

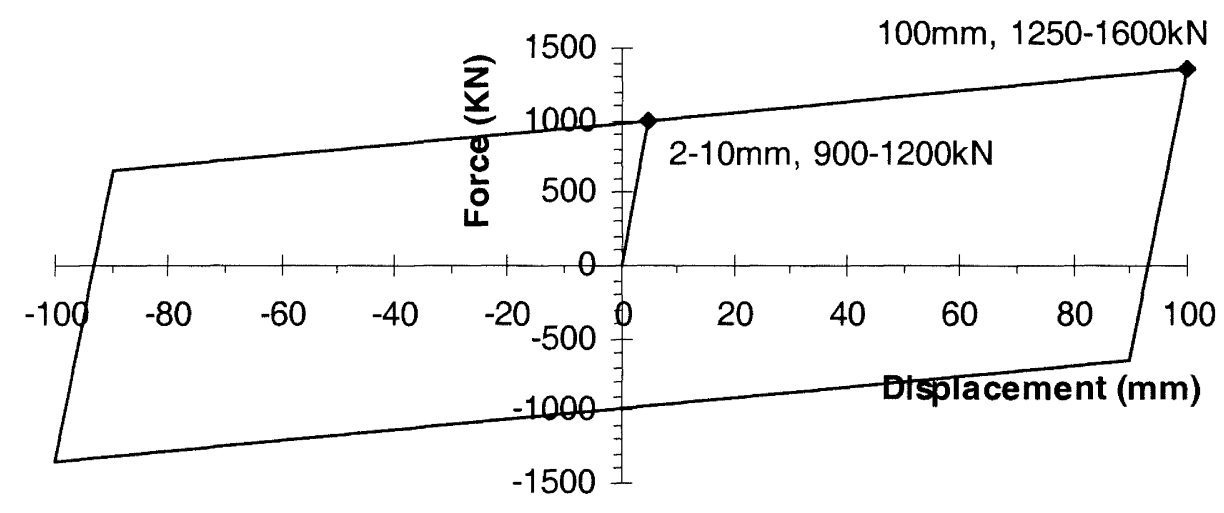

Figure 6. Basic Absorber Force Deflection Curve

Table 2. Bearing Dimensions

\begin{tabular}{|l|l|l|l|l|l|}
\hline $\begin{array}{l}\text { Overall Height } \\
(\mathbf{m m})\end{array}$ & $\begin{array}{l}\text { Overall Plan } \\
\text { Dimension } \\
(\mathbf{m m})\end{array}$ & $\begin{array}{l}\text { Shim Plan } \\
\text { Dimension } \\
(\mathbf{m m})\end{array}$ & $\begin{array}{l}\text { Lead Core } \\
\text { Diameter } \\
(\mathbf{m m})\end{array}$ & $\begin{array}{l}\text { Number of } \\
\text { Rubber } \\
\text { Layers }\end{array}$ & $\begin{array}{l}\text { Rubber } \\
\text { Thickness }(\mathbf{m m})\end{array}$ \\
\hline 207 & 1020 & 1000 & $4 @ 190$ & 10 & 10 \\
\hline
\end{tabular}

The parameters of the bearings designed to meet these requirements are listed in Table 2. To ensure the bearing behaviour satisfied the requirements illustrated in Fig. 6 a testing regime that required 4 cycles to a displacement of 50 $\mathrm{mm}, 4$ cycles to $100 \mathrm{~mm}, 1$ cycle to $150 \mathrm{~mm}$, followed by a further 4 cycles at $50 \mathrm{~mm}$ was devised. The $50 \mathrm{~mm}$ cycle was considered to approximate the level of sustained response likely for the design earthquake event, the $100 \mathrm{~mm}$ cycle represented the maximum likely response of any of the bearings to the design earthquake event (in particular, those at the seaward end of the wharf), while the $150 \mathrm{~mm}$ cycle corresponded to an extreme event to test the integrity of the bearings. The specification required that the bearing be tested at a zero axial load. Two series of tests were performed on the bearings and the results from the $50 \mathrm{~mm}$ displacement cycles are shown in Figure 7. 


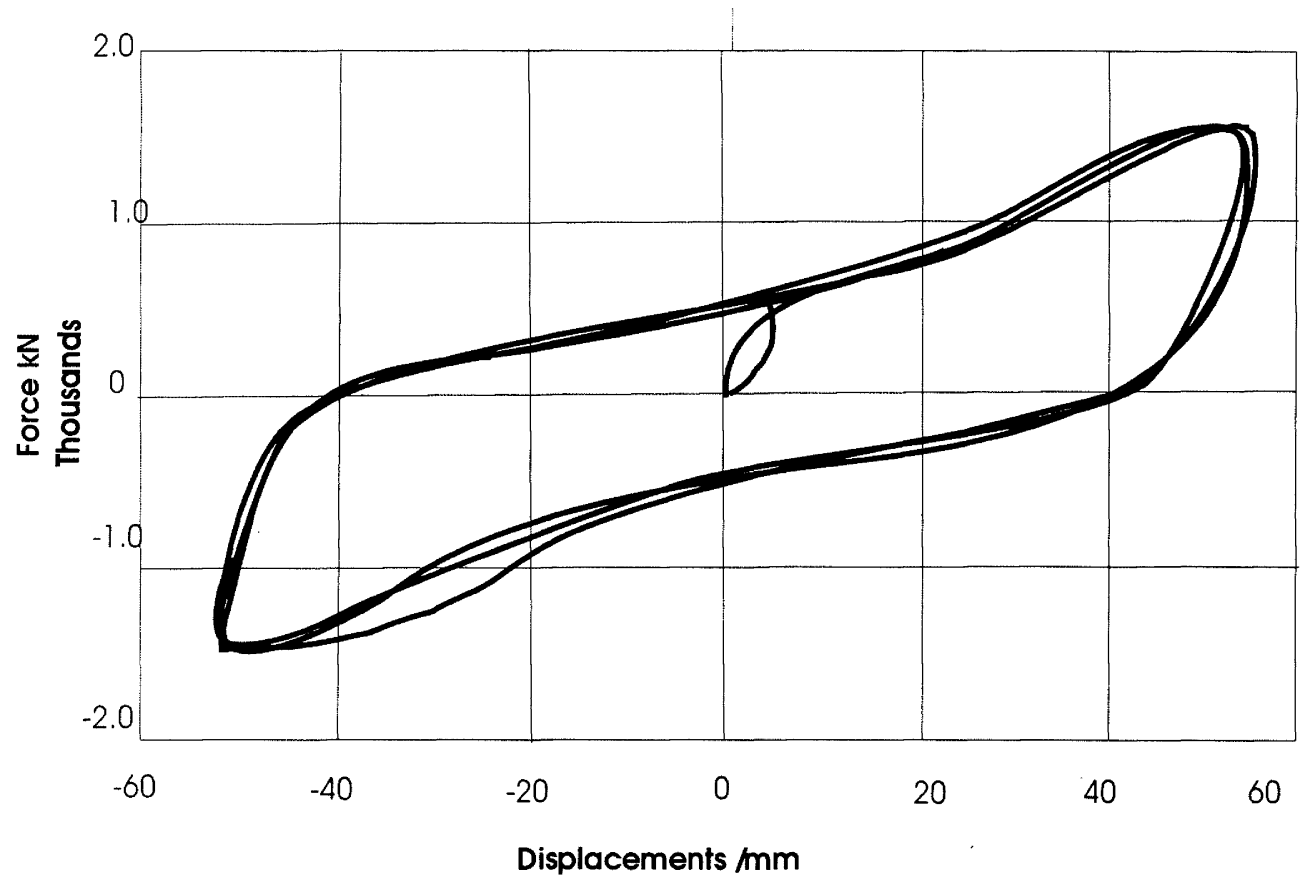

Figure 7(a). Zero Axial Load Test Results

Figure 7(a) shows the results with zero axial load, Fig. 7(b) with the bearing constrained from moving in the axial direction. In the second test the confining axial load varied, but averaged about $1300 \mathrm{kN}$. As a result of these tests a number of characteristics of the bearing behaviour were of concern. Of foremost concern, and illustrated in Fig.7(a), was the pinched nature of the loops for the bearings with no axial load. These loops were more pinched than the design specification, with the area beneath the force-displacement curves dropping to approximately $76 \%$ of the design theoretical value. When constrained vertically, the areas of the curves satisfied the design criterion. Further dynamic analyses, which modelled the experimentally determined hysteretic curves for the bearings with no axial load, indicated a $27 \%$ increase in displacement of the wharf. This was not acceptable. In addition, the very low stiffness on initial loading, and the much higher strength of the bearing at the maximum displacement of the first cycle were perceived as undesirable characteristics. It was feared that the initial low stiffness could allow for larger wharf displacements and the greater strength of the bearings would lead to an overload of the raking piles.

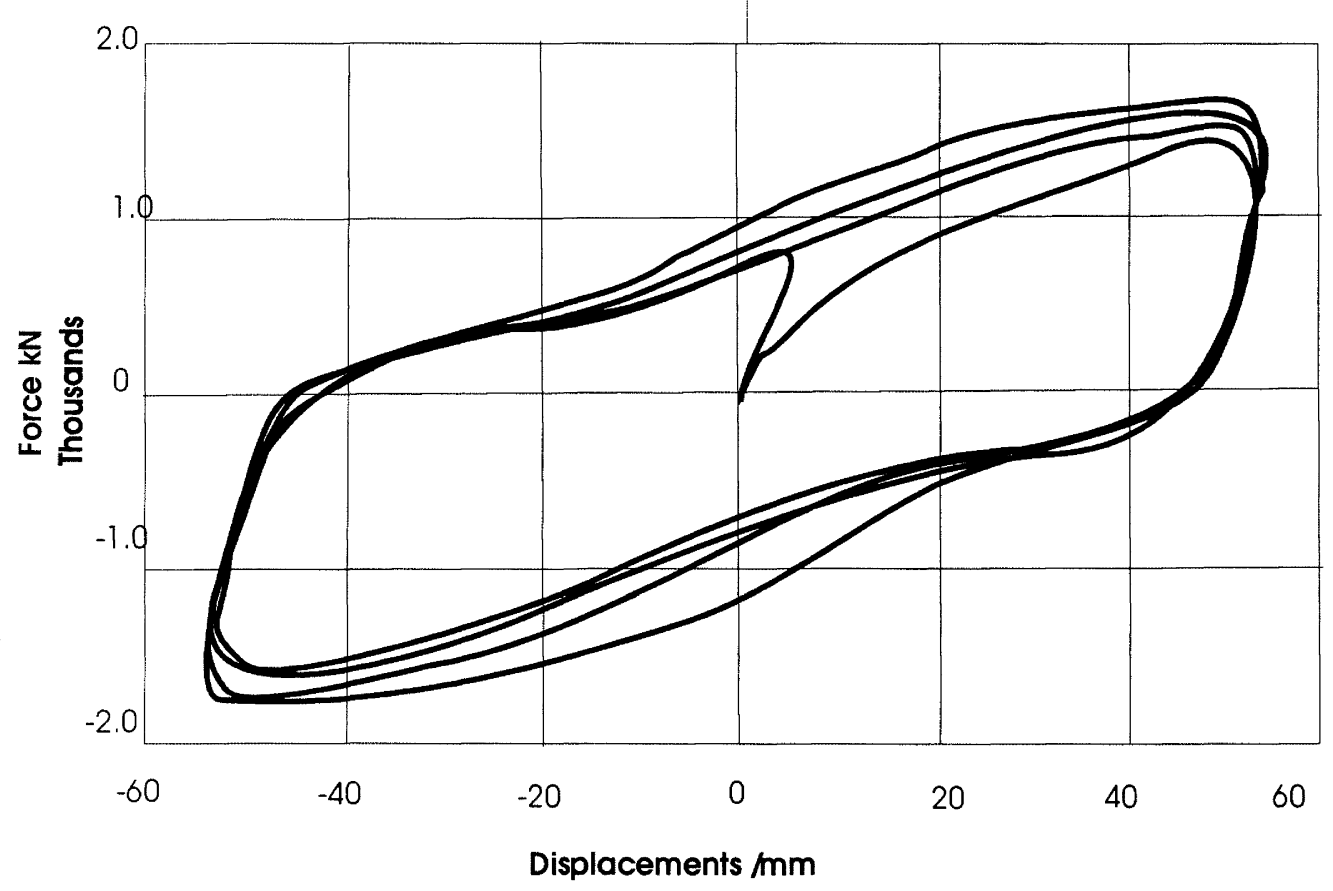

Figure 7(b). Bearing Constrained Test Results 
To assist in overcoming the perceived problems with the bearing performance at zero axial load a number of modifications were made. These included reducing the stiffness of the rubber to help reduce the bearing strength at the larger displacements, and installing the bearings with an axial constraint. This was achieved by using four $32 \mathrm{~mm}$ diameter stressing bars that were sleeved through the pile cap to allow for the bearing movement. The details of a bearing installation are shown in Figure 8. The pretension forces in the bars were relatively low but the bars provide a vertical constraint to the bearings and enable them to perform in a similar manner to the results recorded in the constrained tests.

\section{CONCLUSIONS}

The seismic retrofit of the Princes wharf required a solution to address the lack of reinforcement in the existing vertical piles. The scheme chosen was to provide additional lateral support to the wharf and so restrict the displacements of the piles to within their nominal elastic response. This was achieved in the form of 15 groups of raking piles fastened to the wharf via lead-rubber bearings acting as energy absorbers. Alternative "elastic" raking pile solutions were found to attract much larger forces as to become uneconomical.

Cyclic tests on the lead-rubber bearings at zero axial load showed performance characteristics that were deemed undesirable. The most critical being that the area under the hysteretic curve of the bearing was found to be less than the expected design value. As a consequence, the design of the pile heads of the raking piles has been modified to allow for the bearings to be constrained by tensioned stressing bars.

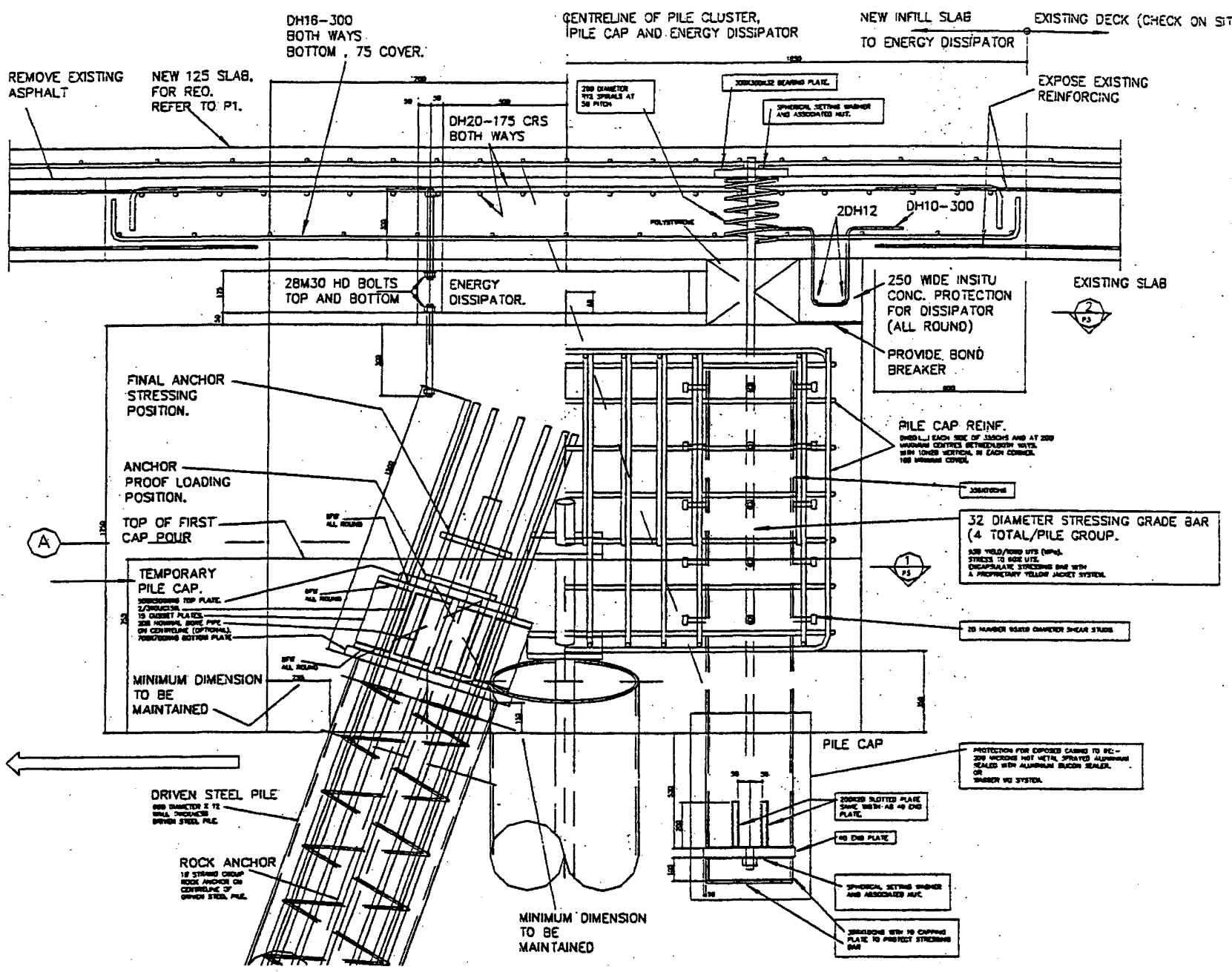

Figure 8. Detail for Seating Bearing 


\section{REFERENCES}

Concrete Structures Standard (1995). New Zealand Standards Association.

Beca, Carter, Hollings and Ferner (1996). Princes Wharf Seismic Hazard Assessment, May .

Tonkin and Taylor (1997). Revision to Preliminary Geotechnical report for the Proposed Stage One Redevelopment at Princes Wharf, Sept.

NZNSEE (1996), The Assessment and Improvement of the Structural Performance of Earthquake Risk Buildings, Draft June.

Priestley, Seible and Calvi (1996), Seismic Design and Retrofit of Bridges, Wiley Interscience.

NZS 4203:1992, Code of practice for General Structural Design and Design Loadings for Buildings, Standards New Zealand.

Monti, M.D., et al (1998) Development and Application of a 100 tonne Damper, NZNSEE Technical Conference, Wairakei, March. 